\title{
RAPID SURVEI KEANEKARAGAMAN HAYATI STATUS KONSERVASI PERMEN LHK (P.106/2018) dan IUCN DI AREAL NILAI KONSERVASI TINGGI PERKEBUNAN KELAPA SAWIT
}

\author{
Erwin Dafis Nasution ${ }^{1,2}$ dan Hairul Fatah ${ }^{3}$ \\ ${ }^{1}$ Wilmar Internasional Plantation, Kabupaten Seruyan, Kalimantan Tengah. \\ ${ }^{2}$ Program Studi Agribisnis, Fakultas Pertanian Universitas Darwan Ali. \\ ${ }^{3}$ HCV Sustainability Wilmar Internasional Plantation, Kabupaten Seruyan \\ Kalimantan Tengah. \\ E-Mail: dafis.nasution1970@gmail.com
}

\begin{abstract}
ABSTRAK
Rapid Survei Keanekaragaman Hayati Status Konservasi Permen LHK (P.106/2018) dan IUCN di areal Nilai Konservasi Tinggi Perkebunan Kelapa Sawit. Adanya kawasan nilai konservasi tinggi (NKT) di dalam areal perkebunan menjadi syarat wajib bagi perkebunan kelapa sawit berkelanjutan yang memiliki sertifikat RSPO ataupun ISPO. Penelitian ini penting untuk di lakukan karena, sampai saat ini kajian mengenai keanekaragaman makhluk hidup di kawasan NKT perkebunan kelapa sawit masih sangat kurang.. Penelitian ini di lakukan pada bulan Oktober 2020 di PT. RHS, Provinsi Kalimantan Tengah. Data yang di kumpulkan berupa keragaman tumbuhan (Flora) dan lima jenis hewan (Fauna) yaitu hewan Mamalia, Reptil, Aves, Amfibi dan Pisces. Penelitian ini bertujuan untuk mengetahui status konservasi keragaman makhluk hidup di kawasan Nilai Konservasi Tinggi di perkebunan Kelapa Sawit menurut status konservasi KemLHK No. 106 tahun 2018 dan IUCN (International Union for Conservation and Natural Resources). Metode penelitian yang digunakan yaitu melalui pengamatan secara langsung untuk keragaman binatang dengan teknik Total Count, Tabel 10 Jenis dan tangkapan Kamera Trap sedangkan untuk keragaman tumbuhan di lakukan dengan teknik plot segi empat $20 \times 100$ meter. Hasil kajian menunjukkan bahwa terdapat 14 Jenis Mamalia, 1 Reptil, 24 Burung dan 11 Jenis tumbuhan yang termasuk ke dalam status perlindungan menurut KemLHK No. 106 tahun 2018. Sedangkan menurut status konservasi IUCN terdapat 2 jenis mamalia dan 3 jenis tumbuhan yang termasuk kategori kritis (CR); 2 jenis Mamalia, 2 jenis Reptil dan 2 jenis tumbuhan yang termasuk kategori rentan terancam punah (EN); 9 jenis mamalia, 2 jenis reptil dan 8 jenis tumbuhan yang termasuk kategori terancam punah (VU); 17 jenis burung dan 2 jenis ikan yang termasuk dalam kategori hampir terancam punah (NT).
\end{abstract}

Kata kunci : Kelapa Sawit, Keragaman Makhluk Hidup, NKT.

\begin{abstract}
Rapid Biodiversity Survey of LHK Permen Conservation Status (P.106/2018) and IUCN in the area of High Conservation Value of Oil Palm Plantations. The existence of high conservation value areas (HCV) in plantation areas becomes a mandatory requirement for sustainable oil palm plantations that have RSPO or ISPO certificates. This research is important to do because, until now, studies on the diversity of living things in the HCV area of oil palm plantations are still lacking.. This research was conducted in October 2020 at PT. RHS, Central Kalimantan Province. The data collected was in the form of diversity of plants (flora) and five types of animals (fauna), namely Mammals, Reptiles, Aves, Amphibians and Pisces. This study aims to determine the conservation status of the biodiversity in High Conservation Value areas in oil palm plantations according to the conservation status of the Ministry of Environment and Forestry No. 106 of 2018 and IUCN (International Union for Conservation and Natural Resources). The research method used is through direct observation for the diversity of animals with the Total Count technique, Table 10 Types and Camera Trap capture, while for plant diversity it is done with a $20 \times 100$ meter rectangular plot technique. The results of the study showed that there were 14 types of Mammals, 1 Reptile, 24 Birds and 11 species of plants which were included in the protection status according to the Ministry of Environment and Forestry No. 106 of 2018. According to the IUCN, there are 2 types of mammals and 3 types of plants which are categorized as endangered (CR); 2 types of Mammals, 2 types of Reptiles and 2 types of plants which are
\end{abstract}


included in the Endangered (EN) category; 9 types of Mammals, 2 types of reptiles and 8 species of plants which are included in the Vulnerable (VU) category; 17 bird species and 2 fish species are classified as Near threatened (NT).

Key words : Biodiversity, HCV, Palm Oil.

\section{PENDAHULUAN}

Salah satu ancaman terbesar dari kerusakan hutan dan hilangnya keanekaragaman makhluk hidup adalah adanya pengembangan perkebunan kelapa sawit (Fitzherbert et al., 2008). Tingginya produktivitas, biaya produksi rendah dan stabil menjadikan kelapa sawit sebagai minyak nabati yang digunakan secara luas di seluruh dunia, dan produksi global terus mengalami peningkatan seiring dengan bertambahnya jumlah penduduk di ikuti juga dengan munculnya peraturan untuk penggunaan minyak sawit sebagai bahan bakar biofuels (Koh et al., 2008; Petrenko et al., 2016). Pada awalnya pembukaan kebun kelapa sawit dilakukan di lahan bekas pertanian dan hutan sekunder bekas loging namun karena keberadaan lahan pertanian yang terbatas praktek perkebunan kelapa sawit telah beralih ke hutan hujan tropis yang masih alami (Austin et al., 2019; Gibbs et al., 2007).

Dalam upaya mengurangi dampak kerusakan pengembangan perkebunan kelapa sawit maka dibentuklah badan sertifikasi nasional seperti ISPO (Indonesian on Sustainable Palm Oil) dan internasional seperti RSPO (Roundtable on Sustainable Palm Oil). ISPO dan RSPO ada sebagai upaya untuk memberikan tanggapan terhadap berbagai permasalahan lingkungan maupun sosial di berbagai negara penghasil minyak kelapa sawit dengan mempromosikan produksi minyak sawit yang berkelanjutan (Jonas et al., 2017). Di dalam perkebunan kelapa sawit yang tersertifikasi ISPO dan RSPO salah satu syaratnya adalah menyediakan sebagian lahannya sebagai areal nilai konservasi tinggi (NKT) (Kathrin et al., 2014).

Dengan adanya perkebunan kelapa sawit ini maka perlu dilakukan kajian keberadaan kawasan nilai konservasi sebagai dasar bagi pengelolaan kawasan NKT dan guna mendukung keberadaan perkebunan kelapa sawit berkelanjutan. Proses pengelolaan kawasan NKT ini bisa dilakukan dengan baik jika terdapat ketersediaan data yang cukup dan akurat (Nurjannah et al., 2016). Adapun salah satu aspek penting bagi pengumpulan data yang di perlukan untuk proses pengelolaan berupa keragaman makhluk hidup yang ada di dalam kawasan NKT tersebut (Nahlunnisa et al., 2016).

Tujuan dari penelitian ini adalah untuk mengetahui status keberadaan dari keragaman makhluk hidup lima kelompok binatang (Fauna) yaitu Mamalia, Reptil, Aves, Amfibi, dan Pisces serta keragaman tumbuhan (Flora) menurut status konservasi kementerian lingkungan hidup atau Permen LHK tahun 2018 (MENLHK, 2018) dan status konservasi IUCN (International Union for Conservation and Natural Resources) atau Lembaga internasional yang mengeluarkan status konservasi satwa dan tumbuhan.

\section{METODA PENELITIAN}

\subsection{Tempat dan Waktu}

Survey dilaksanakan pada tanggal 7 s/d 14 Oktober 2020, pada area HCV di PT RHS Group dengan nilai hcv 1,2,3,4 dan 5. Data pendukung lainnya menggunakan data hasil monitoring, patroli dan pengukuran 
lahan/ klaim masyarakat, maupun

hasil kamera trap di HCV.

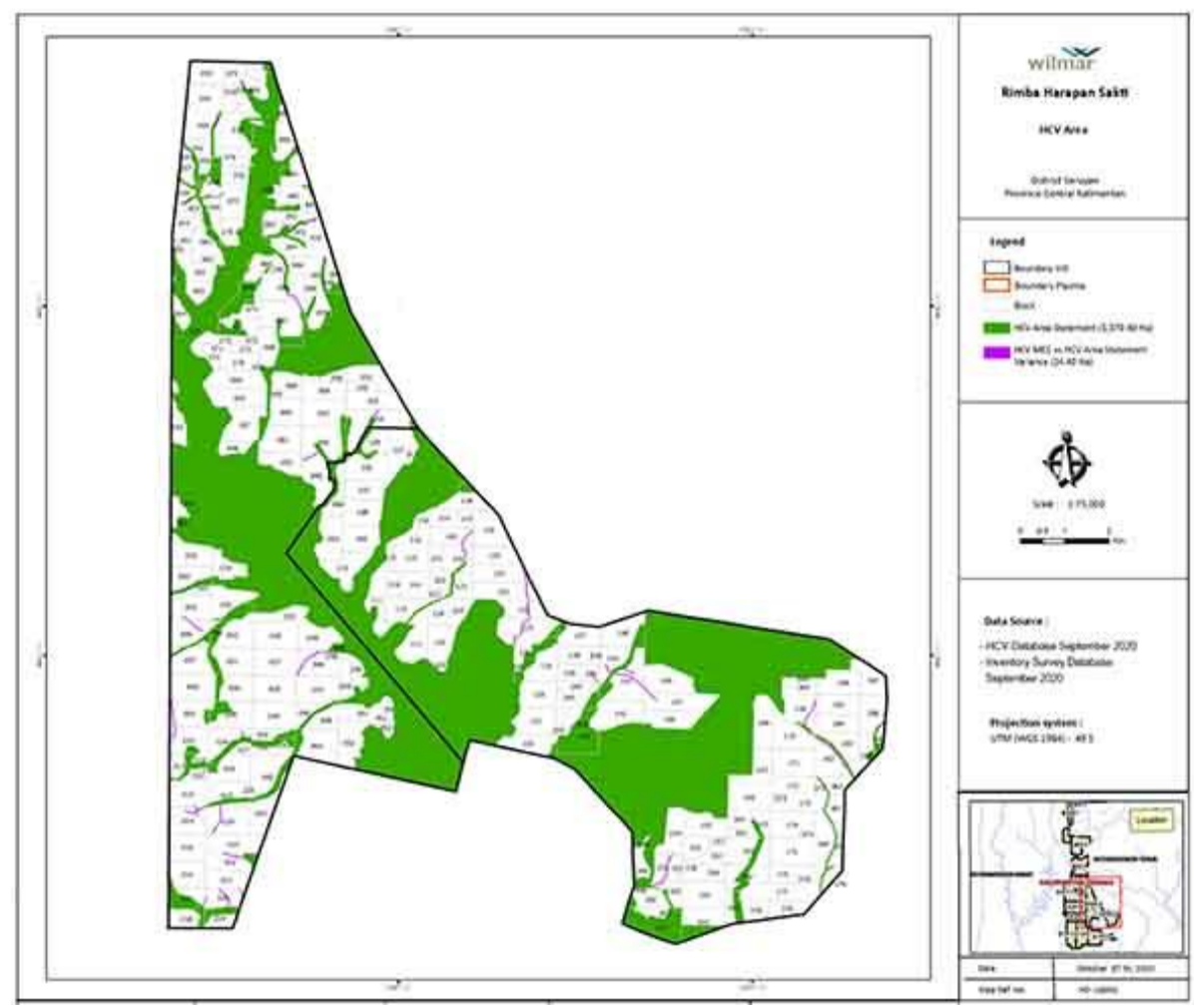

Gambar 1. Peta lokasi pengambilan data penelitian.

2.2. Bahan dan Alat

Adapun alat dan bahan yang digunakan dalam penelitian ini adalah Buku catatan lapangan (Sebagai lembar data) dan alat tulis, Binokular, Kamera, Mobil operasional lapangan HCV, GPS dan buku panduan lapangan (Francis, 2019; Inger, 2005; MacKinnon et al., 2010; Phillipps, 2016; Stuebing et al., 1999). Kemudian untuk kegiatan pengolahan data dilakukan dengan komputer yaitu melalui aplikasi Microsoft Excel.

\subsection{Metode Pengumpulan Data}

\subsubsection{Total Count}

Dimana seluruh satwa liar yang ditemui, baik langsung (direct sighting) maupun tidak langsung (indirect sighting, Egg, Footprint, feses, sound, nest) dicatat dalam buku lapangan.

\subsubsection{Tabel 10 Jenis (MacKinnon Seri $S K J B)$}

Merupakan modifikasi dari metode yang dikembangkan oleh MacKinnon. Teknik pengambilan data adalah berjalan mengikuti sebuah jalur dan mencatat setiap pertemuan dengan satwa liar (terutama burung) dan memasukkannya dalam tabel yang masing-masing berisi 10 jenis satwa liar. Jika dalam satu tabel sudah berisi 10 jenis satwa, maka pencatatan beralih ke tabel berikutnya. Satwa yang teramati dan tercatat di tabel pertama, kemudian teramati lagi pada waktu pengambilan tabel kedua, tetap dicatat dalam tabel kedua tersebut. Demikian seterusnya hingga batasan waktu atau area yang ditentukan telah selesai (MacKinnon et al., 2010).

\subsubsection{Tangkapan Kamera Trap}

Pemasangan kamera trap di lakukan pada area HCV pada kategori satu dengan mempertimbangkan adanya jalur satwa 
liar dan tidak menghadap matahari secara langsung.

\subsubsection{Identifikasi Flora}

Untuk flora dilakukan dengan cara dibuat plot segi empat dengan ukuran 20 x $100 \mathrm{~m}$, di ukur tinggi dan keliling pohon yang berada dalam plot termasuk jenisnya. Ini bertujuan untuk mengetahui kerapatan pohon secara global dan untuk mengetahui jenis - jenis pohon yang dominan dan jenis pohon sebagai pakan satwa liar.

\subsection{Analisis Data}

Hasil temuan lapangan akan dibuat ke dalam bentuk tabel disesuaikan dengan taksa dan jenisnya. Mengupdate status satwa liar di IUCN dan mengategorikan satwa liar yang masuk ke dalam perlindungan menurut peraturan Menteri Lingkungan Hidup dan Kehutanan nomor 106 tahun 2018 (MENLHK, 2018).

Untuk status konservasi menurut Kementerian Lingkungan Hidup dan kehutanan nomor 106 tahun 2018 maka di bagi ke dalam dua kelompok yaitu Dilindungi (D) dan Tidak Dilindungi (TD). Sedangkan menurut status perlindungan IUCN di bagi ke dalam 9 kelompok status yaitu (Vié et al., 2009) :

1. Extinct atau sudah dinyatakan punah (Ex).

2. Extinct in the wild atau sudah di nyatakan punah di alam namun masih di temukan di penangkaran (EW).

3. Ciritically atau kritis (CR).

4. Endangered atau terancam punah/genting (EN).

5. Vulnerable atau rentan terancam punah (VU).

6. Near threatened atau hampir terancam punah (NT).

7. Least concern atau resiko rendah (LC).

\section{Data Deficient/ Informasi kurang (DD) \\ 9. Not Evaluated atau belum masuk IUCN Redlist (NE).}

\section{HASIL PENELITIAN DAN PEMBAHASAN}

\subsection{Keanekaragaman Fauna}

\subsubsection{Mamalia}

Selama kegiatan Rapid survei pada tahu 2020, teridentifikasi sebanyak 27 jenis mamalia yang berada di area HCV PT RHS baik yang dijumpai secara langsung maupun tidak langsung (sarang, jejak kaki, feses, cakaran dan bekas makanan) sehingga terdapat 4 penambahan jenis spesies yaitu babi hutan yang sebelumnya hanya teridentifikasi babi jenggot. Jenis mamalia yang teridentifikasi tersebut terdapat 14 jenis diantaranya masuk ke dalam status perlindungan berdasarkan PERMEN LHK No. 106 tahun 2018.

Sedangkan berdasarkan pada status perlindungan IUCN terdapat 2 jenis mamalia yang termasuk ke dalam kelompok kritis (CR) yaitu Orang utan Kalimantan (Pongo pygmaeus), Trenggiling (Manis javanica); 2 jenis mamalia dalam kelompok terancam punah (EN) yaitu Owa jenggot putih (Hylobates albibarbis) Bekantan (Nasalis larvatus); dan 9 jenis mamalia yang termasuk kedalam kelompok rentan terancam punah (VU). Selain itu terdapat pula 5 jenis mamalia yang merupakan endemik Kalimantan yaitu Bekantan (nasalis larvatus), Bajing tanah ekor tegak (Rheithrosciurus macrotis), Kelasi (Presbytis rubicunda), Orang utan Kalimantan (Pongo pygmaeus), Owa jenggot putih (Hylobates albibarbis). 
Tabel 1. Spesies Mamalia Teridentifikasi di tahun 2020 PT.RHS

\begin{tabular}{|c|c|c|c|c|c|}
\hline \multirow{2}{*}{ No. } & \multicolumn{2}{|c|}{ Nama Spesies } & \multicolumn{2}{|c|}{ Status Perlindungan } & \multirow[b]{2}{*}{ Endemisitas } \\
\hline & Nama Ilmiah & Nama Lokal & $\begin{array}{l}\text { IUCN } \\
2020.1\end{array}$ & $\begin{array}{l}\text { Permen LHK } \\
\text { No. 106/2018 }\end{array}$ & \\
\hline 1 & Calosiurus notatus & Bajing kelapa & LC & $\mathrm{TD}$ & \\
\hline 2 & Nasalis larvatus & Bekantan & $\mathrm{EN}$ & $\mathrm{TD}$ & Endemic \\
\hline 3 & Lutrogale perspicillata & Berang-berang & VU & $\mathrm{D}$ & \\
\hline 4 & Tragulus javanicus & pelanduk & LC & $\mathrm{D}$ & \\
\hline 5 & Muntiacus muntjak & Kijang & $\mathrm{LC}$ & $\mathrm{D}$ & \\
\hline 6 & Tarsius bancanus & Tarsius & VU & $\mathrm{D}$ & \\
\hline 7 & Arctogalidia trivirgata & Musang akar & LC & $\mathrm{TD}$ & \\
\hline 8 & Sus barbatus & Babi berjenggot & VU & TD & \\
\hline 9 & Rheithrosciurus macrotis & Bajing-tanah ekor-tegak & VU & $\mathrm{TD}$ & Endemik \\
\hline 10 & Helarctos malayanus & Beruang madu & VU & $\mathrm{D}$ & \\
\hline 11 & Macaca nemestrina & Beruk & VU & $\mathrm{TD}$ & \\
\hline 12 & Tragulus kanchil & Kancil & LC & $\mathrm{D}$ & \\
\hline 13 & Presbytis rubicunda & Kelasi & VU & $\mathrm{D}$ & Endemik \\
\hline 14 & Muntiacus muntjak & Kijang muntjak & LC & $\mathrm{D}$ & \\
\hline 15 & Prionailurus bengalensis & Kucing kuwuk & LC & $\mathrm{D}$ & \\
\hline 16 & Hystrix brachyura & Landak raya & LC & $\mathrm{D}$ & \\
\hline 17 & Macaca fascicularis & Monyet ekor panjang & VU & $\mathrm{TD}$ & \\
\hline 18 & Paradoxurus hermaphroditus & Musang luak & LC & TD & \\
\hline 19 & Pongo pygmaeus & Orangutan kalimantan & $\mathrm{CR}$ & $\mathrm{D}$ & Endemik \\
\hline 20 & Hylobates albibarbis & Owa jenggot putih & $\mathrm{EN}$ & $\mathrm{D}$ & Endemik \\
\hline 21 & Rusa unicolor & Rusa sambar & VU & $\mathrm{D}$ & \\
\hline 22 & Rattus tiomanicus & Tikus Belukar & LC & $\mathrm{TD}$ & \\
\hline 23 & Rattus tanezumi & Tikus Rumah & $\mathrm{LC}$ & $\mathrm{TD}$ & \\
\hline 24 & Manis javanica & Trenggiling & $\mathrm{CR}$ & $\mathrm{D}$ & \\
\hline 25 & Tupaia glis & Tupai akar & LC & $\mathrm{TD}$ & \\
\hline 26 & Tupaia tana & Tupai Tanah & $\mathrm{LC}$ & TD & \\
\hline 27 & Sus scrofa & Babi Hutan & LC & $\mathrm{TD}$ & \\
\hline
\end{tabular}

\subsubsection{Reptile}

Hasil identifikasi reptil pada kegiatan Rapid survey pada tahun 2020 ter data sebanyak 21 jenis. Jenis reptil di PT RHS merupakan reptil yang toleran dan sering ditemui diwilayah pinggiran hutan dan perkebunan. Data spesies reptil diambil dari kawasan HCV dan sebagian lagi dari pertemuan langsung di jalan lintas blok dan $\mathrm{HCV}$, pendataan ini juga berkaitan dengan reptil yang masuk kedalam blok kegiatan operasional kebun. dengan adanya pendataan ini dapat disampaikan pada saat sosialisasi terkait keberadaan satwa dan tindakan yang harus dilakukan apabila bertemu dengan satwa tersebut.
Dari jenis reptil yang teridentifikasi terdapat 1 jenis reptil yang termasuk dalam perlindungan berdasarkan PERMEN LHK No. 106 tahun 2018 yaitu Buaya Muara (Crocodylus porosus) dan 20 jenis sisanya tidak masuk dalam perlindungan. Sedangkan menurut status perlindungan IUCN terdapat 2 jenis reptil yang termasuk kedalam kelompok terancam punah (EN) yaitu Kura batok (Cuora amboinensis), Kura-kura duri (Heosemys spinosa) dan 2 jenis reptil yang termasuk dalam kelompok rentan terancam punah (VU) yaitu Bulus/labilabi (Amyda cartilaginea), Ular king kobra (Ophiophagus hannah), sedangkan 
17 jenis lainnya masih berada dalam kelompok risiko rendah (LC) yaitu diantaranya Biawak Air, Buaya muara, Bunglon, Cicak Rumah, Kadal Kebun, Ular Air, Ular Cincin Mas, Ular sanca,
Ular Dipung, Ular Senduk, Ular Welang, ular semak, Kadal rumput, Ular pelangi, Ular Segitiga merah, ular tikus, Ular birang.

Tabel 2. Spesies Reptil Teridentifikasi di tahun 2020 PT.RHS

\begin{tabular}{|c|c|c|c|c|c|}
\hline \multirow[b]{2}{*}{ No. } & \multicolumn{2}{|c|}{ Nama Spesies } & \multicolumn{2}{|c|}{ Status Perlindungan } & \multirow[b]{2}{*}{ Endemisitas } \\
\hline & Nama Ilmiah & Nama Lokal & $\begin{array}{c}\text { IUCN } \\
2020\end{array}$ & $\begin{array}{l}\text { Permen LHK } \\
\text { No. 106/2018 }\end{array}$ & \\
\hline 1 & Varanus salvator & Biawak Air & $\mathrm{LC}$ & TD & \\
\hline 2 & Crocodylus porosus & Buaya muara & $\mathrm{LC}$ & $\mathrm{D}$ & \\
\hline 3 & Amyda cartilaginea & Bulus/labi-labi & VU & $\mathrm{TD}$ & \\
\hline 4 & Calotes versicolor & Bunglon & $\mathrm{LC}$ & TD & \\
\hline 5 & Hemidactylus frenatus & Cicak Rumah & $\mathrm{LC}$ & TD & \\
\hline 6 & Eutropis multifasciata & Kadal Kebun & $\mathrm{LC}$ & TD & \\
\hline 7 & Cuora amboinensis & Kura batok & $\mathrm{EN}$ & TD & \\
\hline 8 & Enhydris enhydris & Ular Air & $\mathrm{LC}$ & TD & \\
\hline 9 & Boiga dendrophila & Ular Cincin Mas & $\mathrm{LC}$ & TD & \\
\hline 10 & Phyton reticulatus & Ular sanca & $\mathrm{LC}$ & TD & \\
\hline 11 & Phyton breitensteini & Ular Dipung & $\mathrm{LC}$ & TD & Endemik \\
\hline 12 & Naja sumatrana & Ular Senduk & $\mathrm{LC}$ & TD & \\
\hline 13 & Bungarus candidus & Ular Welang & $\mathrm{LC}$ & TD & \\
\hline 14 & Liopeltis tricolor & ular semak & $\mathrm{LC}$ & TD & \\
\hline 15 & Ophiophagus hannah & Ular king kobra & VU & TD & \\
\hline 16 & Takydromus sexlineatus & Kadal rumput & $\mathrm{LC}$ & TD & \\
\hline 17 & Xenopeltis unicolor & Ular pelangi & $\mathrm{LC}$ & TD & \\
\hline 18 & Xenochrophis triangulerus & Ular Segitiga merah & $\mathrm{LC}$ & TD & \\
\hline 19 & Heosemys spinosa & Kura-kura duri & EN & TD & \\
\hline 20 & Elaphe flavolineata & ular tikus & $\mathrm{LC}$ & TD & \\
\hline 21 & Oligodon oktolineatus & Ular birang & LC & TD & \\
\hline
\end{tabular}

\subsubsection{Aves}

Dari hasil pendataan spesies burung (aves) yang pernah dilakukan sebelumnya pada tahun 2018 ter data 105 spesies burung yang pernah ditemui di PT RHS dan pada tahun 2019 teridentifikasi sebanyak 107 spesies data hasil monitoring dan rapid survey, tambahan jenis yang eksistensinya ditemukan adalah Cekakak Suci atau Cekakak Australia (Todiramphus sanctus) dan srigunting batu (Dicrurus paradiseus). Sedangkan di tahun 2020 terdapat tambahan data spesies yang dijumpai di PT RHS diantaranya pergam hijau (Ducula aenea), cabai merah (Dicaeum cruentatum nigrimentum), kacamata biasa (Zosterops palpebrosus buxtoni), kuntul kecil (Egretta garzetta), pelanduk dada putih (Trichastoma rostratum) dan kangkareng perut putih (Anthracoceros albirostris).
Dari semua jenis aves tersebut terdapat 20 jenis burung yang dilindungi PERMEN LHK No. 106 Tahun 2018 antara lain Elang Bondol, Elang brontok, Elang tikus, Elang-alap jambul, Alapalap, Elangular-bido, Elang bondol, Burung madu-sriganti, Burung madu kelapa, Burung madu belukar, Burung madu sepah-raja, Burung madu-rimba, Raja udang-meninting, Kipasan belang, Tiong emas dan Kangkareng-hitam, Cekakak Belukar, Cekakak Sungai, cekakak suci, sriguntig batu, paruh kodok, kangkareng perut putih dan Alapalap Capung.

Menurut status perlindungan IUCN terdapat 17 jenis burung yang termasuk kedalam kelompok hampir terancam punah (NT), dan 96 jenis lainnya maih berada dalam kelompok risiko rendah (LC). 
Tabel 3. Spesies Aves Teridentifikasi di tahun 2020 PT.RHS

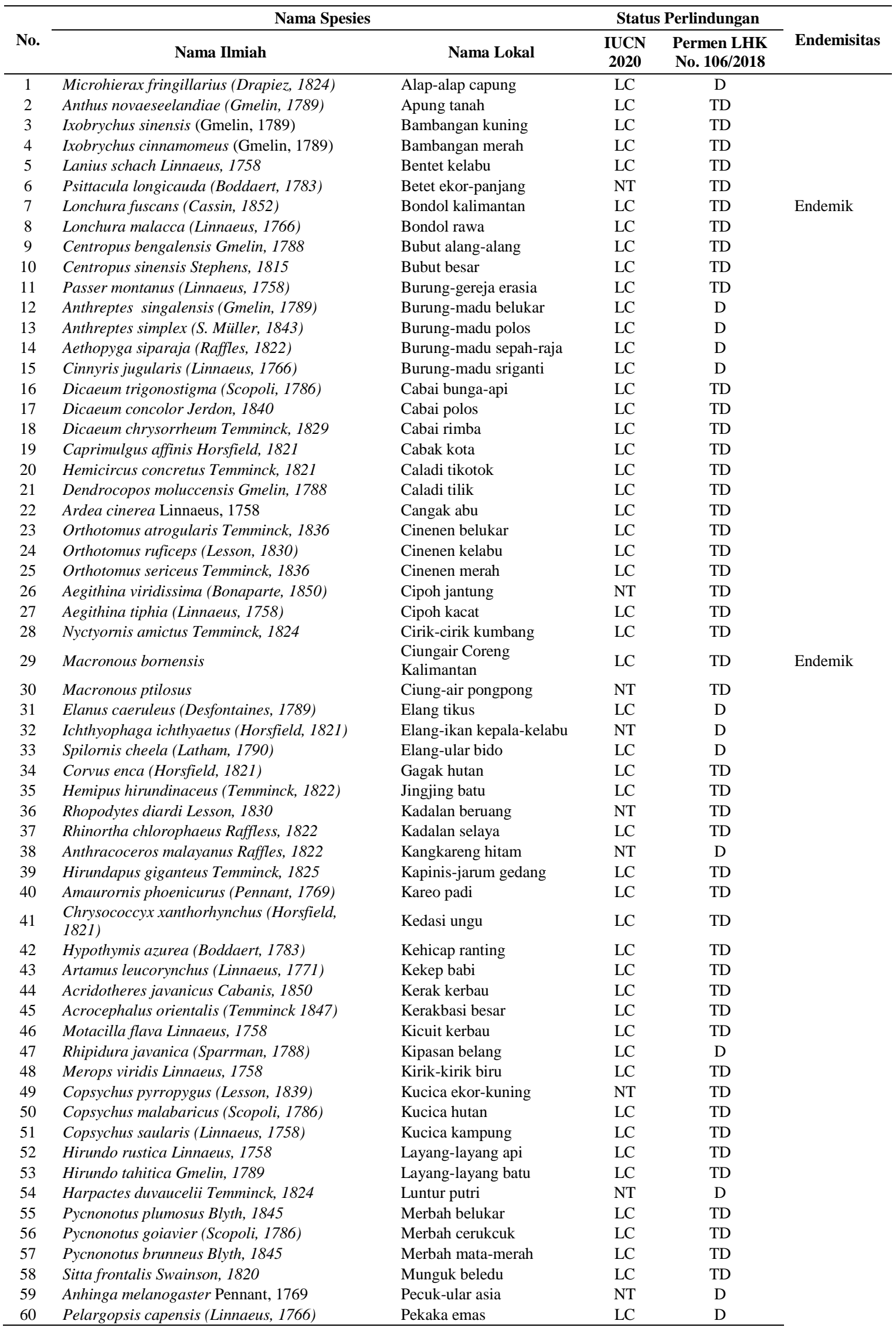




\begin{tabular}{|c|c|c|c|c|c|}
\hline \multirow[b]{2}{*}{ No. } & \multicolumn{2}{|l|}{ Nama Species } & \multicolumn{2}{|c|}{ Status Perlindungan } & \multirow[b]{2}{*}{ Endemisitas } \\
\hline & Nama Ilmiah & Nama Lokal & $\begin{array}{c}\text { IUCN } \\
2020\end{array}$ & $\begin{array}{l}\text { Permen LHK } \\
\text { No. 106/2018 }\end{array}$ & \\
\hline 61 & Malacocincla malaccense (Hartlaub, 1844) & Pelanduk ekor-pendek & LC & TD & \\
\hline 62 & Malacocincla sepiarium (Horsfield, 1821) & Pelanduk semak & LC & TD & \\
\hline 63 & Pellorneum capistratum (Temminck, 1823) & Pelanduk topi-hitam & $\mathrm{LC}$ & TD & \\
\hline 64 & Dryocopus javensis Horsfield, 1821 & Pelatuk ayam & $\mathrm{LC}$ & $\mathrm{TD}$ & \\
\hline 65 & Dinopium javanense Ljungh, 1797 & Pelatuk besi & $\mathrm{LC}$ & TD & \\
\hline 66 & Prionochilus percussus (Temminck, 1826) & Pentis pelangi & LC & TD & \\
\hline 67 & Prionochilus maculatus (Temminck, 1836) & Pentis raja & LC & TD & \\
\hline 68 & Prinia flaviventris (Delessert, 1840) & Perenjak rawa & LC & $\mathrm{TD}$ & \\
\hline 69 & Arachnothera longirostra (Latham, 1790) & Pijantung kecil & $\mathrm{LC}$ & $\mathrm{D}$ & \\
\hline 70 & Treron vernans (Linnaeus, 1771) & Punai gading & LC & TD & \\
\hline 71 & Treron curvirostra (Gmelin, 1789) & Punai lengguak & LC & TD & \\
\hline 72 & Alcedo meninting Horsfield, 1821 & Raja-udang meninting & LC & $\mathrm{D}$ & \\
\hline 73 & Pericrocotus solaris Blyth, 1846 & Sepah dagu-kelabu & LC & TD & \\
\hline 74 & Pericrocotus igneus Blyth, 1846 & Sepah tulin & NT & TD & \\
\hline 75 & Tyto alba Scopoli, 1769 & Serak jawa & LC & TD & \\
\hline 76 & Loriculus galgulus (Linnaeus, 1758) & Serindit melayu & LC & TD & \\
\hline 77 & Ficedula westermanni (Sharpe, 1888) & Sikatan belang & LC & TD & \\
\hline 78 & Rhinomyias umbratilis (Strickland, 1849) & Sikatan-rimba dada-kelabu & NT & $\mathrm{TD}$ & \\
\hline 79 & Dicrurus aeneus Vieillot, 1817 & Srigunting keladi & LC & $\mathrm{TD}$ & \\
\hline 80 & Calorhamphus fuliginosus Temminck, 1830 & Takur ampis & LC & TD & \\
\hline 81 & Megalaima chrysopogon Temminck, 1824 & Takur gedang & LC & TD & \\
\hline 82 & Megalaima australis Horsfield, 1821 & Takur tenggeret & LC & TD & \\
\hline 83 & Megalaima rafflesii Lesson, 1839 & Takur tutut & NT & TD & \\
\hline 84 & Platysmurus leucopterus (Temminck, 1824) & Tangkar kambing & NT & $\mathrm{TD}$ & \\
\hline 85 & Streptopelia chinensis (Scopoli, 1786) & Tekukur biasa & LC & TD & \\
\hline 86 & Stachyris nigricollis (Temminck, 1836) & Tepus kaban & NT & TD & \\
\hline 87 & Stachyris erythroptera(Blyth, 1842) & Tepus merbah-sampah & LC & TD & \\
\hline 88 & Gracula religiosa Linnaeus, 1758 & Tiong emas & LC & $\mathrm{D}$ & \\
\hline 89 & Sasia abnormis Temminck, 1825 & Tukik tikus & LC & TD & \\
\hline 90 & Collocalia linchi (Horsfield \& F. Moore, 1854) & Walet linci & LC & TD & \\
\hline 91 & Collocalia fuciphagus Thunberg, 1821 & Walet sarang-putih & LC & TD & \\
\hline 92 & Alcippe brunneicauda & Wergan coklat & NT & TD & \\
\hline 93 & Cacomantis merulinus (Scopoli, 1786) & Wiwik kelabu & LC & TD & \\
\hline 94 & Halcyon smyrnensis & Cekakak belukar & LC & $\mathrm{D}$ & \\
\hline 95 & Todirhamphus chloris & Cekakak sungai & LC & $\mathrm{D}$ & \\
\hline 96 & Pericrocotus flammeus & Sepah hutan & LC & TD & \\
\hline 97 & Haliastur indus & Elang Bondol & LC & $\mathrm{D}$ & \\
\hline 98 & Dicrurus remifer & Srigunting batu & LC & TD & \\
\hline 99 & Eurystomus orientalis & Tiong lampu biasa & LC & TD & \\
\hline 100 & Coracina striata & Kepudang Sungu sumatra & LC & $\mathrm{TD}$ & \\
\hline 101 & Reinwardtipicus validus & Pelatuk Kundang & LC & TD & \\
\hline 102 & Abroscopus superciliaris & Cikrak bambu & LC & TD & \\
\hline 103 & Batrachostomus stellatus & Paruh Kodok bintang & NT & $\mathrm{D}$ & \\
\hline 104 & Caprimulgus macrurus & Cabak Maling & LC & $\mathrm{TD}$ & \\
\hline 105 & Nisaetus cirrhatus & Elang Brontok & $\mathrm{LC}$ & $\mathrm{D}$ & \\
\hline 106 & Todiramphus sanctus & Cekakak suci/australi & $\mathrm{LC}$ & $\mathrm{D}$ & \\
\hline 107 & Dicrurus paradiseus & srigunting batu & $\mathrm{LC}$ & $\mathrm{D}$ & \\
\hline 108 & Ducula aenea & Pergam hijau & $\mathrm{LC}$ & $\mathrm{TD}$ & \\
\hline 109 & Dicaeum cruentatum nigrimentum & Cabai merah & $\mathrm{LC}$ & TD & \\
\hline 110 & Zosterops palpebrosus buxtoni & kacamata biasa & $\mathrm{LC}$ & TD & \\
\hline 111 & Egretta garzetta & Kuntul kecil & LC & TD & \\
\hline 112 & Trichastoma rostratum & Pelanduk dada putih & LC & TD & \\
\hline 113 & Anthracoceros albirostris (Shaw, 1807) & kangkareng perut putih & NT & $\mathrm{D}$ & \\
\hline
\end{tabular}

\subsubsection{Amphibi}

Perjumpaan secara langsung dengan Amfibi pada tanggal 7-14 Oktober 2020, teridentifikasi lima jenis yaitu Kongkang kolam (Hylarana chalconota), Bangkong rawa (Ingerophrynus quadriporcatu),
Kodok rawa gambut (Pseudobufo subasper), Katak Tegalan (Fejervarya limnocharis), Kongkang kelenjar (Hylarana glandulosa). Kelima jenis Amphibi tersebut tidak masuk dalam status perlindungan menurut permen 
LHK 106 tahun 2018. Dan merurut status perlindungan IUCN kelima jenis katak tersebut masih berada di dalam kelompok risiko rendah (LC)

Tabel 4. Spesies Amphibi Teridentifikasi di tahun 2020 PT.RHS

\begin{tabular}{|c|c|c|c|c|c|}
\hline \multirow[b]{2}{*}{ No. } & \multicolumn{2}{|c|}{ Nama Species } & \multicolumn{2}{|c|}{ Status Perlindungan } & \multirow[b]{2}{*}{ Endemisitas } \\
\hline & Nama Ilmiah & Nama Lokal & $\begin{array}{l}\text { IUCN } \\
2020.1\end{array}$ & $\begin{array}{c}\text { Permen LHK } \\
\text { No. 106/2018 }\end{array}$ & \\
\hline 1 & Hylarana chalconota & Kongkang kolam & $\mathrm{LC}$ & $\mathrm{TD}$ & \\
\hline 2 & Ingerophrynus quadriporcatus & Bangkong rawa & LC & TD & \\
\hline 3 & Pseudobufo subasper & Kodok rawa gambut & LC & TD & \\
\hline 4 & Fejervarya limnocharis & Katak Tegalan & $\mathrm{LC}$ & TD & \\
\hline 5 & Hylarana glandulosa & Kongkang kelenjar & $\mathrm{LC}$ & $\mathrm{TD}$ & \\
\hline
\end{tabular}

\subsubsection{Piscess}

Keanekaragaman jenis ikan di kawasan NKT khususnya di daerah aliran sungai alami di PT RHS pada tahun 2018 terdapat 40 jenis ikan yang pernah ter data pada riparian dan sungai Pukun, sedangkan dari kegiatan survey 2019 ter data 51 jenis ikan yang ter data, dan untuk tahun 2020 terdapat 2 tambahan jenis teridentifikasi eksis di perairan sungai Pukun diantaranya ikan pipih Borneo dan ikan graminang 2 sehingga total 53 jenis ikan pernah teridentifikasi di perairan yang ada di kawasan NKT PT RHS.
Dari 53 jenis ikan yang telah teridentifikasi tersebut tidak ada satupun yang termasuk kedalam kelompok perlindungan menurut Permen LHK No. 106 tahun 2018. Sedangkan menurut status perlindungan IUCN 39 jenis diantaranya masuk kedalam kelompok risiko rendah (LC), 7 jenis ikan masuk kedalam kelompok informasi kurang (DD) dan 5 jenis lainnya berada dalam kelompok belum masuk IUCN Redlist atau Sudah terdata namun belum ada penelitian lebih lanjut sejak identifikasi pertama.

Tabel 5. Spesies Jenis Ikan Teridentifikasi di tahun 2020 PT.RHS

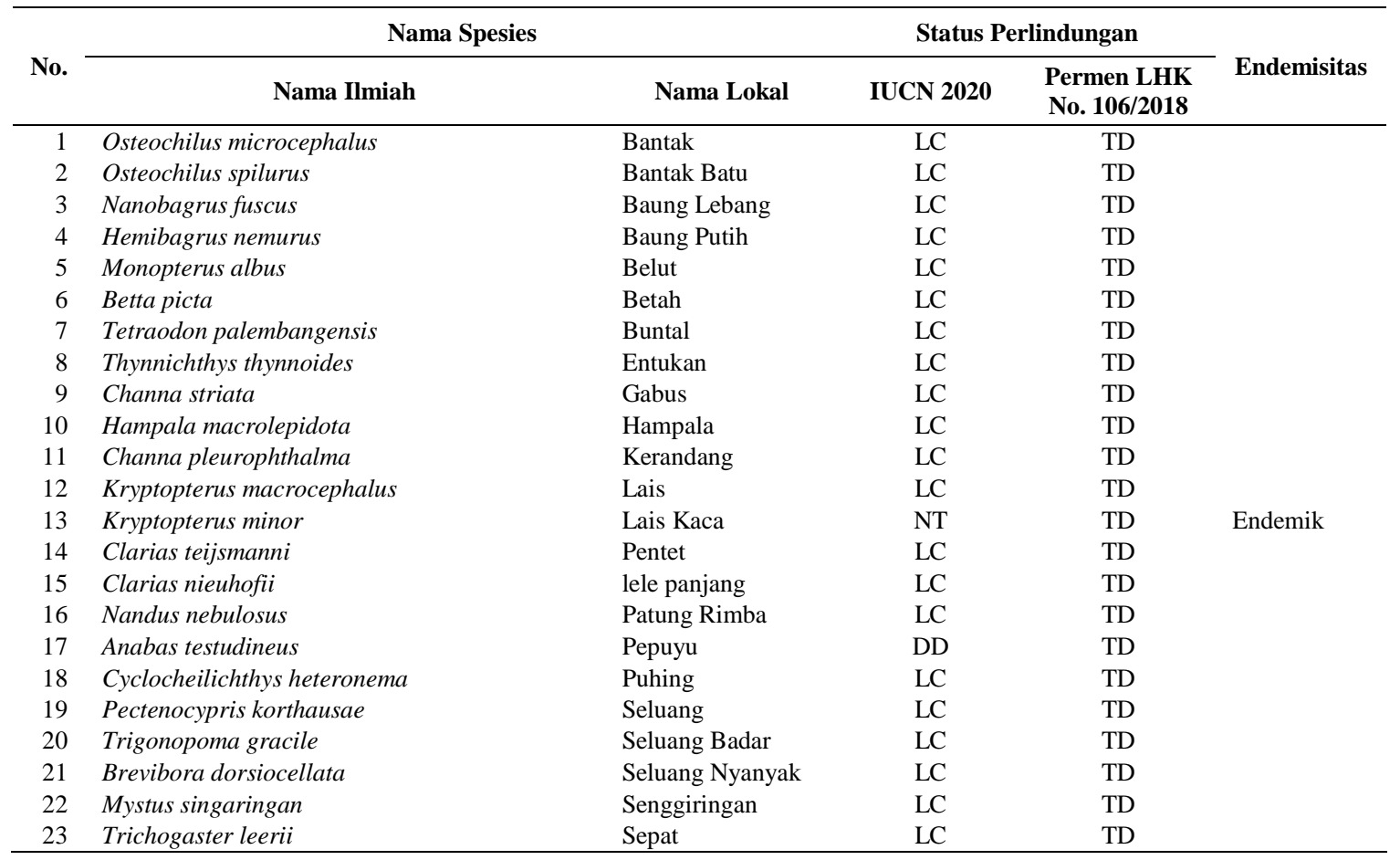




\begin{tabular}{|c|c|c|c|c|c|}
\hline \multirow[b]{2}{*}{ No. } & \multicolumn{2}{|l|}{ Nama Spesies } & \multicolumn{2}{|c|}{ Status Perlindungan } & \multirow[b]{2}{*}{ Endemisitas } \\
\hline & Nama Ilmiah & Nama Lokal & IUCN 2020 & $\begin{array}{c}\text { Permen LHK } \\
\text { No. 106/2018 }\end{array}$ & \\
\hline 24 & Trichogaster trichopterus & Sepat intik & $\mathrm{LC}$ & TD & \\
\hline 25 & Homaloptera orthogoniata & Susuh Batang & $\mathrm{LC}$ & $\mathrm{TD}$ & \\
\hline 26 & Wallago leerii & Tapah & $\mathrm{LC}$ & TD & \\
\hline 27 & Mastacembelus erythrotaenia & Tilan & LC & TD & \\
\hline 28 & Macrognathus aculeatus & Tilan Kelokoi & $\mathrm{LC}$ & $\mathrm{TD}$ & \\
\hline 29 & Channa micropeltes & Toman & $\mathrm{LC}$ & $\mathrm{TD}$ & \\
\hline 30 & Belontia hasselti (Cuvier 1831) & kapar & $\mathrm{DD}$ & $\mathrm{TD}$ & \\
\hline 31 & Betta editha & tampela & $\mathrm{NE}$ & $\mathrm{TD}$ & \\
\hline 32 & Channa bankanensis (Bleeker 1853) & mehau & DD & $\mathrm{TD}$ & \\
\hline 33 & Puntius lineatus (duncker 1904) & Puyau & DD & TD & \\
\hline 34 & Puntius rhomboocellatus(Koumans 1940 ) & graminang & DD & $\mathrm{TD}$ & Endemik \\
\hline 35 & Chaca bankanensis & terapu & LC & $\mathrm{TD}$ & \\
\hline 36 & Cyclocheilichthys janthochir (Bleeker 1853) & Jampal & DD & $\mathrm{TD}$ & \\
\hline 37 & Channa lucius & Kemancung/runtu & $\mathrm{LC}$ & $\mathrm{TD}$ & \\
\hline 38 & Pristolepis grooti & Patung & $\mathrm{NE}$ & $\mathrm{TD}$ & \\
\hline 39 & Monotrete leiurus & Buntal & $\mathrm{LC}$ & TD & \\
\hline 40 & Luciocephalus pulcher & julung besar & $\mathrm{LC}$ & TD & \\
\hline 41 & Betta raja & Tempela & LC & $\mathrm{TD}$ & \\
\hline 42 & Sphaerichtys selatanensis & Biji Waluh & NT & $\mathrm{TD}$ & \\
\hline 43 & Nandus nebulosus & Tambubuk & $\mathrm{LC}$ & TD & \\
\hline 44 & Hemirhamphodon chrysopunctatus & julang- julung kecil & NE & TD & \\
\hline 45 & Rasbora kalochroma & seluang kecil & $\mathrm{LC}$ & TD & \\
\hline 46 & Rasbora volzi & seluang kecil & $\mathrm{LC}$ & $\mathrm{TD}$ & \\
\hline 47 & puntius gemellus & Puyau & $\mathrm{LC}$ & TD & \\
\hline 48 & Rasbora dorsiocellata & Seluang & $\mathrm{LC}$ & TD & \\
\hline 49 & Tichogaster microlepis (Ghunter 1861) & sapat & $\mathrm{NE}$ & $\mathrm{TD}$ & \\
\hline 50 & Rasbora cephalotaenia & Seluang & $\mathrm{NE}$ & $\mathrm{TD}$ & \\
\hline 51 & Rasbora pauciperforata & $\begin{array}{l}\text { Seluang garis } \\
\text { merah }\end{array}$ & LC & TD & \\
\hline 52 & Chitala borneensis & Pipih & $\mathrm{LC}$ & $\mathrm{TD}$ & \\
\hline 53 & Puntius foerschi & graminang & DD & TD & Endemik \\
\hline
\end{tabular}

\subsection{Keanekaragaman Flora}

Identifikasi tumbuhan dilakukan dengan metode line transect di kawasan HCV PT Rimba Harapan Sakti. Tumbuhan yang diidentifikasi adalah dengan kategori tiang-pohon (diameter > $20 \mathrm{~cm}$ ) yang masuk dalam transect. Terdapat 111 spesies tumbuhan yang teridentifikasi selama pendataan 2020 .

Dari hasil identifikasi tersebut terdapat 11 jenis tumbuhan yang termasuk dalam status perlindungan Permen LHK No. 106 tahun 2018 yaitu diantaranya Putat (Barringtonia sp), Tabari/Ehang (Diospyros siamang), Rengas (Gluta rengas), Papung (Sandoricum beccarianum), Sasapat (Santirea sp), Belangeran/Kahui (Shorea belangeran), Meranti rawa (Shorea rassa), Bengkirai (Shorea laevis), Meranti (Shorea leprosula), jahe-jahean (Amomum sp) dan Jahe-jahean (Zingiber ttensii).
Kemudian menurut status perlindungan IUCN terdapat 3 jenis tumbuhan yang termasuk kedalam kelompok kritis (CR) yaitu Ulin (Eusideroxylon zwageri), Belangeran atau Kahui (Shorea elangeran) dan Majau (Shorea palembanica). Kemudian 2 jenis masuk dalam kelompok terancam punah (EN) yaitu Meranti (Shorea leprosula), Meranti Merah (Shorea ovata). Selanjutnya terdapat 8 jenis tumbuhan yang berada dalam kelompok rentan terhadap punah (VU) Keruing (Shorea sp), Jelutung (Dyera costulata), Jelutung rawa (Dyera lowii), Pasak bumi (Euricom longifolia), Ramin (Gonystylus bancanus) Bayur (Pterospermum javanicum), Meranti rawa (Shorea crassa), Sindur/Sepetir/Supa/Kayu galu (Sindora sp). Dan 89 Jenis lainnya masuk dalam kelompok risiko rendah (LC). Dan terdapat 2 janis tumbuhan endemik yaitu Beranang dan Lumba. 
Tabel 6. Spesies Jenis Tumbuhan Teridentifikasi di tahun 2020 PT.RHS

\begin{tabular}{|c|c|c|c|c|c|}
\hline \multirow[b]{2}{*}{ No. } & \multicolumn{2}{|c|}{ Nama Species } & \multicolumn{2}{|c|}{ Status Perlindungan } & \multirow[b]{2}{*}{ Endemisitas } \\
\hline & Nama Ilmiah & Nama Lokal & IUCN 2020 & $\begin{array}{c}\text { Permen LHK } \\
\text { No. 106/2018 }\end{array}$ & \\
\hline 1 & Actinodaphne sp & Madang & LC & TD & \\
\hline 2 & Alseodapne insignes & Gembor & $\mathrm{LC}$ & $\mathrm{TD}$ & \\
\hline 3 & Alstonia sp. & Pulai & $\mathrm{LC}$ & $\mathrm{TD}$ & \\
\hline 4 & Alyxia $s p$ & Akar Klanis & $\mathrm{LC}$ & TD & \\
\hline 5 & Aporusa sp & Hampuak & $\mathrm{LC}$ & $\mathrm{TD}$ & \\
\hline 6 & Arthocarpus integra & Nangka & $\mathrm{LC}$ & $\mathrm{TD}$ & \\
\hline 7 & Baccaurea sp & Kisip & $\mathrm{LC}$ & TD & \\
\hline 8 & Barringtonia sp & Putat & $\mathrm{LC}$ & $\mathrm{TD}$ & \\
\hline 9 & Calophyllum hosei & Bintangur & LC & $\mathrm{TD}$ & \\
\hline 10 & Campnosperma coriaceum & Terantang & $\mathrm{LC}$ & $\mathrm{D}$ & \\
\hline 11 & Canarium $s p$ & Mangga hutan & $\mathrm{LC}$ & $\mathrm{TD}$ & \\
\hline 12 & Castanopsis sp & Pampaning Putih & $\mathrm{LC}$ & TD & \\
\hline 13 & Chisocheton $s p$ & Latak Manuk & $\mathrm{LC}$ & $\mathrm{TD}$ & \\
\hline 14 & Combretocarpus rotuodatus & Tanah-Tanah & $\mathrm{LC}$ & $\mathrm{TD}$ & \\
\hline 15 & Combretocarpus sp & Tumeh & $\mathrm{LC}$ & TD & \\
\hline 16 & Compassia excelsa & Kempas & $\mathrm{CD}$ & TD & \\
\hline 17 & Cotylebium sp & Rasak & $\mathrm{LC}$ & $\mathrm{TD}$ & \\
\hline 18 & Cratoxylum arborescens & Geronggang & $\mathrm{LC}$ & TD & \\
\hline 19 & Cryptocarya sp & Madang & $\mathrm{LC}$ & $\mathrm{TD}$ & \\
\hline 20 & Dactylocladus stenostachys & Mentibu & $\mathrm{LC}$ & $\mathrm{TD}$ & \\
\hline 21 & Dellinea sp & Mengkajang & $\mathrm{LC}$ & $\mathrm{TD}$ & \\
\hline 22 & Dialium $s p$ & Api-api & $\mathrm{LC}$ & $\mathrm{TD}$ & \\
\hline 23 & Diospyros seudomalabarica & Arang-Arang/Kayu arang & $\mathrm{LC}$ & $\mathrm{TD}$ & \\
\hline 24 & Diospyros siamang & Tabari/Ehang & $\mathrm{LC}$ & $\mathrm{TD}$ & \\
\hline 25 & Diospyros $s p$ & Kayu malam/malam-malam & $\mathrm{LC}$ & $\mathrm{TD}$ & \\
\hline 26 & Shorea $s p$ & Keruing & VU & $\mathrm{D}$ & \\
\hline 27 & Durio zibethynus & Durian hutan & $\mathrm{LC}$ & $\mathrm{TD}$ & \\
\hline 28 & Dyera costulata & Jelutung & VU & $\mathrm{TD}$ & \\
\hline 29 & Dyera lowii & Jelutung & VU & $\mathrm{TD}$ & \\
\hline 30 & Elaeocarpus mastersii & Mangkinang Blawau & $\mathrm{LC}$ & $\mathrm{TD}$ & \\
\hline 31 & Knema intermedia & Kerandau & $\mathrm{LC}$ & $\mathrm{TD}$ & \\
\hline 32 & Ilex cymosa & Kambasira/Bansira & $\mathrm{LC}$ & $\mathrm{TD}$ & \\
\hline 33 & Euricoma longifolia & Pasak bumi & VU & $\mathrm{TD}$ & \\
\hline 34 & Eusideroxylon zwageri & Ulin & $\mathrm{CR}$ & TD & \\
\hline 35 & Ficus sp & Kayu ara & & $\mathrm{TD}$ & \\
\hline 36 & Ficus $s p$ & Lonok & & $\mathrm{TD}$ & \\
\hline 37 & Garcinea sp & Manggis hutan & & $\mathrm{TD}$ & \\
\hline 38 & Gluta rengas & Rengas & & $\mathrm{TD}$ & \\
\hline 39 & Syzygium $s p$ & Rengas burung & & $\mathrm{TD}$ & \\
\hline 40 & Gonystylus bancanus & Ramin & VU & $\mathrm{D}$ & \\
\hline 41 & Hibiscus tiliaceus & Waru & $\mathrm{LC}$ & $\mathrm{TD}$ & \\
\hline 42 & Horsfieldia glabra & Kumpang & LC & $\mathrm{TD}$ & \\
\hline 43 & Lithorcarpus beccarianus & Pampaning & $\mathrm{LC}$ & $\mathrm{TD}$ & \\
\hline 44 & Litsea angulata & Medang & LC & $\mathrm{TD}$ & \\
\hline 45 & Macaranga gigantea & Mahang & $\mathrm{LC}$ & $\mathrm{TD}$ & \\
\hline 46 & Macaranga triloba & Mahang & $\mathrm{LC}$ & TD & \\
\hline 47 & Madhuca motleyana & Katiau & LC & $\mathrm{TD}$ & \\
\hline 48 & Melastoma sp & Cengkodok & $\mathrm{LC}$ & $\mathrm{TD}$ & \\
\hline 49 & Melulaeca cajuputi & Galam & $\mathrm{LC}$ & $\mathrm{TD}$ & \\
\hline 50 & Mezzetia parviflora & Pisang pisang besar & $\mathrm{LC}$ & $\mathrm{TD}$ & \\
\hline 51 & Mezzetia umbillata & Kambalitan//pisang-pisang kecil & $\mathrm{LC}$ & $\mathrm{TD}$ & \\
\hline 52 & Nepenthes sp & Kantung semar & $\mathrm{LC}$ & $\mathrm{TD}$ & \\
\hline 53 & Nephellium $s p$ & Renggam/Rambutan & $\mathrm{LC}$ & $\mathrm{TD}$ & \\
\hline 54 & Nothaphoebe umbelliflora & Marsihung & $\mathrm{LC}$ & $\mathrm{TD}$ & \\
\hline 55 & Ochanostachys sp & Benuang & LC & $\mathrm{TD}$ & \\
\hline 56 & Palaquium beccarianum & Nyatoh & $\mathrm{LC}$ & $\mathrm{TD}$ & \\
\hline 57 & Parartocarpus sp & Bantilap & $\mathrm{LC}$ & $\mathrm{TD}$ & \\
\hline 58 & Platea sp. & Mahung/Tambalik angin & LC & $\mathrm{TD}$ & \\
\hline 59 & Polyalthia glauca & Banitan & $\mathrm{LC}$ & $\mathrm{TD}$ & \\
\hline 60 & Polyalthia sumatrana & Mahawai & $\mathrm{LC}$ & $\mathrm{TD}$ & \\
\hline 61 & Pterospermum javanicum & Bayur & VU & $\mathrm{TD}$ & \\
\hline
\end{tabular}




\begin{tabular}{|c|c|c|c|c|c|}
\hline \multirow[b]{2}{*}{ No. } & \multicolumn{2}{|c|}{ Nama Species } & \multicolumn{2}{|c|}{ Status Perlindungan } & \multirow[b]{2}{*}{ Endemisitas } \\
\hline & Nama Ilmiah & Nama Lokal & IUCN 2020 & $\begin{array}{c}\text { Permen LHK } \\
\text { No. 106/2018 } \\
\end{array}$ & \\
\hline 62 & Sandoricum beccarianum & Papung & & $\mathrm{TD}$ & \\
\hline 63 & Santirea $s p$ & Sasapat & & $\mathrm{TD}$ & \\
\hline 64 & Shorea belangeran & Belangeran/Kahui & $\mathrm{CR}$ & $\mathrm{D}$ & \\
\hline 65 & Shorea crassa & Meranti rawa & VU & $\mathrm{D}$ & \\
\hline 66 & Shorea laevis & Bengkirai & LR & $\mathrm{D}$ & \\
\hline 67 & Shorea leprosula & Meranti & EN & D & \\
\hline 68 & Shorea ovata & Meranti Merah & EN & $\mathrm{D}$ & \\
\hline 69 & Shorea palembanica & Majau & $\mathrm{CR}$ & $\mathrm{D}$ & \\
\hline 70 & Sindora $s p$ & Sindur/Sepetir/Supa/Kayu galu & VU & $\mathrm{TD}$ & \\
\hline 71 & Stemonurus scorpiodies & Kepot Bajuku & $\mathrm{LC}$ & $\mathrm{TD}$ & \\
\hline 72 & Syzygium $s p$ & Galam Tikus & $\mathrm{LC}$ & $\mathrm{TD}$ & \\
\hline 73 & Syzygium $s p$ & Ubar putih & $\mathrm{LC}$ & $\mathrm{TD}$ & \\
\hline 74 & Syzygium tawahense & Ubar merah & $\mathrm{LC}$ & $\mathrm{TD}$ & \\
\hline 75 & Tristaniopsis sp. & Belawan Putih & $\mathrm{LC}$ & $\mathrm{TD}$ & \\
\hline 76 & Tetramerista glabra & Punak & $\mathrm{LC}$ & $\mathrm{TD}$ & \\
\hline 77 & Tristaniopsis $s p$ & Melaban & $\mathrm{LC}$ & TD & \\
\hline 78 & Uncarya $s p$ & Akar Putih & $\mathrm{LC}$ & $\mathrm{TD}$ & \\
\hline 79 & Uncarya $s p$ & Bejakah & $\mathrm{LC}$ & $\mathrm{TD}$ & \\
\hline 80 & Vitex pubescens & Leban & $\mathrm{LC}$ & $\mathrm{TD}$ & \\
\hline 81 & Willughbeia $s p$ & Akar dangu & $\mathrm{LC}$ & $\mathrm{TD}$ & \\
\hline 82 & Xanthophyllum $s p$ & Kambasira & $\mathrm{LC}$ & $\mathrm{TD}$ & \\
\hline 83 & Xanthophyllum $s p$ & Kemuning & $\mathrm{LC}$ & $\mathrm{TD}$ & \\
\hline 84 & Xerospermum sp & Piais & $\mathrm{LC}$ & $\mathrm{TD}$ & \\
\hline 85 & Xilopia malayana & Jangkang & $\mathrm{LC}$ & TD & \\
\hline 86 & Archidendron $s p$ & Jengkol hutan & $\mathrm{LC}$ & TD & \\
\hline 87 & Artobotries $s p$ & Akar Bejakah & $\mathrm{LC}$ & $\mathrm{TD}$ & \\
\hline 88 & Baccaurea sp & Kisip & $\mathrm{LC}$ & $\mathrm{TD}$ & \\
\hline 89 & Barringtonia sp & Putat & $\mathrm{LC}$ & $\mathrm{TD}$ & \\
\hline 90 & Beilschimedia $s p$ & Gimor/Gemor & $\mathrm{LC}$ & $\mathrm{TD}$ & \\
\hline 91 & Evodia $s p$ & Kayu bangu & $\mathrm{LC}$ & TD & \\
\hline 92 & Imperata silindrica & Ilalang & $\mathrm{LC}$ & $\mathrm{TD}$ & \\
\hline 93 & Psychotria sp & & $\mathrm{LC}$ & $\mathrm{TD}$ & \\
\hline 94 & Pternandra cordata & Sirih-sirih/pasolan & LC & $\mathrm{TD}$ & \\
\hline 95 & Sterculia $s p$ & Kelumpang & $\mathrm{LC}$ & $\mathrm{TD}$ & \\
\hline 96 & Trema cannabina & & $\mathrm{LC}$ & $\mathrm{TD}$ & \\
\hline 97 & Tristaniopsis merguensis Griff. & Palawan & $\mathrm{LC}$ & $\mathrm{TD}$ & \\
\hline 98 & Canarium $s p$ & pantis & $\mathrm{LC}$ & TD & \\
\hline 99 & Pternandra spp & Habu & $\mathrm{LC}$ & TD & \\
\hline 100 & Dillenia spp & Simpur & $\mathrm{LC}$ & $\mathrm{TD}$ & \\
\hline 101 & Pinnata spp & Kedondong hutan & $\mathrm{LC}$ & $\mathrm{TD}$ & \\
\hline 102 & Curcuma longa $L$ & kunyit hutan & $\mathrm{LC}$ & $\mathrm{TD}$ & \\
\hline 103 & Hornstedtia schypifera & Beranang & $\mathrm{LC}$ & $\mathrm{TD}$ & Endemic \\
\hline 104 & Hornstedtia conica & Lumba & $\mathrm{LC}$ & TD & Endemic \\
\hline 105 & Атотит sp & jahe-jahean & $\mathrm{LC}$ & TD & \\
\hline 106 & Zingiber ottensii & Jahe-jahean & LC & $\mathrm{TD}$ & \\
\hline 107 & Nepenthes gracilis & kantong warik & $\mathrm{LC}$ & $\mathrm{D}$ & \\
\hline 108 & Nepenthes ampularia & kantong warik & LC & $\mathrm{D}$ & \\
\hline 109 & Artocapus anisophyllus & Mentawa & $\mathrm{LC}$ & $\mathrm{TD}$ & \\
\hline 110 & Mangiera magnifica & Asam Putaran & $\mathrm{LC}$ & $\mathrm{TD}$ & \\
\hline 111 & Nephellium lappaceum & Rambutan & $\mathrm{LC}$ & $\mathrm{TD}$ & \\
\hline
\end{tabular}

\section{KESIMPULAN}

Dari hasil kajian yang telah dilakukan dapat disimpulkan bahwa terdapat 14 Jenis Mamalia, 1 Reptil, 24 Burung dan 11 Jenis tumbuhan yang termasuk kedalam status perlindungan menurut KemLHK No. 106 tahun 2018.
Sedangkan menurut status konservasi IUCN terdapat 2 jenis mamalia dan 3 jenis tumbuhan yang termasuk kategori kritis (CR); 2 jenis Mamalia, 2 jenis Reptil dan 2 jenis tumbuhan yang termasuk kategori terancam punah (EN); 9 jenis mamalia, 2 jenis reptil dan 8 jenis tumbuhan yang termasuk kategori rentan terancam punah (VU); 17 jenis burung 
dan 2 jenis ikan yang termasuk dalam kategori hampir terancam punah (NT).

\section{DAFTAR PUSTAKA}

Austin, K. G., Schwantes, A., Gu, Y., \& Kasibhatla, P. S. (2019). What causes deforestation in Indonesia? Environmental Research Letters. doi: 10.1088/1748-9326/aaf6db

Fitzherbert, E. B., Struebig, M. J., Morel, A., Danielsen, F., Brühl, C. A., Donald, P. F., \& Phalan, B. (2008). How will oil palm expansion affect biodiversity? In Trends in Ecology and Evolution. doi: 10.1016/j.tree.2008.06.012

Francis, C. (2019). Field guide to the mammals of South-east Asia. Bloomsbury Publishing.

Gibbs, H. K., Brown, S., Niles, J. O., \& Foley, J. A. (2007). Monitoring and estimating tropical forest carbon stocks: Making REDD a reality. Environmental Research Letters. doi: 10.1088/1748-9326/2/4/045023

Inger, R. F. (2005). A field guide to the frogs of Borneo. Kota Kinabalu: Natural History Publications (Borneo) in association with ....

Jonas, H., Abram, N. K., \& Ancrenaz, M. (2017). Addressing the impact of large-scale oil palm plantations on orangutan conservation in Borneo. Retrieved from https://www.researchgate.net/public ation/318728005

Kathrin, A., \& Fridel, H. (2014). Minyak Kelapa Sawit BerkelanjutanTuntutan atau Realitas: Potensi dan Keterbatasan Roundtable on Sustainable Palm Oil. Berlin: Brot fur die Welt.
Koh, L. P., \& Wilcove, D. S. (2008). Is oil palm agriculture really destroying tropical biodiversity? Conservation Letters. doi: 10.1111/j.1755-263x.2008.00011.x

MacKinnon, J., Phillipps, K., \& Van Balen, B. (2010). Burung-burung di Sumatera, Jawa, Bali dan Kalimantan. Burung Indonesia. Bogor.

MENLHK. (2018). Perubahan Kedua Atas Peraturan Menteri Lingkungan Hidup Dan Kehutanan Nomor P.20/MENLHK/SETJEN/KUM.1/6/ 2018 Tentang Jenis Tumbuhan Dan Satwa Yang Dilindungi. Kementrian Lingkungan Hidup. Retrieved from http://jdih.menlhk.co.id/uploads/files /P_106_2018_JENIS_TSL_menlhk_ 07252019152513.pdf

Nahlunnisa, H., Zuhud, E. A. M., \& Santosa, Y. (2016). Keanekaragaman spesies tumbuhan di arealnilai konservasi tinggi (nkt) perkebunan kelapa sawit provinsi riau. Media Konservasi, 21(1), 9198.

Nurjannah, S., Amzu, E., \& Sunkar, A. (2016). Peran Kawasan Bernilai Konservasi Tinggi Bagi Pelestarian Keanekaragaman Hayati di Perkebunan Kelapa Sawit Provinsi Riau. RISALAH KEBIJAKAN PERTANIAN DAN LINGKUNGAN Rumusan Kajian Strategis Bidang Pertanian Dan Lingkungan, 3(1), 68-77.

Petrenko, C., Paltseva, J., \& Searle, S. (2016). Ecological impacts of palm oil expansion in Indonesia. White Pater.

Phillipps, Q. (2016). Phillipps' field guide to the mammals of Borneo and their ecology: Sabah, Sarawak, Brunei, and Kalimantan (Vol. 105). Princeton University Press. 
Stuebing, R. B., Inger, R. F., \& Tan, F. L. (1999). Field guide to the snakes of Borneo. Natural History Publications (Borneo).
N. (2009). Wildlife in a changing world: an analysis of the 2008 IUCN Red List of threatened species. IUCN.

Vié, J.-C., Hilton-Taylor, C., \& Stuart, S. 